\title{
Recanalization of the Native Artery in Patients with Bypass Failure
}

\author{
Roberto Gandini - Roberto Chiappa - Massimiliano Di Primio • \\ Livio Di Vito · Luca Boi · Erdembileg Tsevegmid · Giovanni Simonetti
}

Received: 12 October 2008/Accepted: 28 July 2009/Published online: 29 August 2009

(C) Springer Science+Business Media, LLC and the Cardiovascular and Interventional Radiological Society of Europe (CIRSE) 2009

\begin{abstract}
Our objective was to evaluate the possible role of endovascular recanalization of occluded native artery after a failed bypass graft in the case of either acute or chronic limb-threatening ischemia otherwise leading to amputation. In a single-center retrospective clinical analysis, from January 2004 to March 2007 we collected 31 consecutive high-surgical-risk patients (32 limbs) with critical limb ischemia following late ( $>30$ days after surgery) failure of open surgery bypass graft reconstruction. All patients deemed unfit for surgery underwent tentative endovascular recanalization of the native occluded arterial tract. The mean follow-up period was 24 (range, 6-42) months. Technical success was achieved in $30(93.7 \%)$ of 32 limbs. The cumulative primary assisted patency calculated by Kaplan-Meyer analysis was $92 \%$ and $88 \%$, respectively, at 12 and 24 months. The limb salvage rate approached $90 \%$ at 30 months. In conclusion, our experience shows the feasibility of occluded native artery endovascular recanalization after a failed bypass graft, with optimal results in terms of midterm arterial patency and limb salvage. Our opinion is that successful recanalization of the arterial tract previously considered unsuitable for endovascular approach is allowed by improved competency and experience of vascular specialists, as well as the advances made in catheter and guidewire technology. This group of patients would previously have been relegated to
\end{abstract}

R. Gandini - R. Chiappa - M. Di Primio - L. Di Vito - L. Boi ·

E. Tsevegmid · G. Simonetti

Department of Diagnostic Imaging, Interventional Radiology,

Molecolar Imaging and Radiotherapy, University of Rome Tor

Vergata, Viale Oxford 81, 00133 Rome, Italy

R. Chiappa $(\bowtie)$

Via Sorano 30, 00178 Rome, Italy

e-mail: robchiap@gmail.com repeat bypass grafts, with their inherently inferior patency and recognized added technical demands. We recognize previous surgical native artery disconnection and lack of pedal runoff to be the main cause of technical failure.

Keywords Native artery - Bypass failure .

Endovascular recanalization

\section{Introduction}

Despite continued advances in vascular surgical techniques and resultant improvement in infrainguinal bypass graft patency, thrombosis of femoropopliteal and femorotibial bypass grafts remains a distressing and challenging problem for all vascular surgeons. Early graft failure ( $<30$ days after surgery) has been reported in $5 \%$ to $20 \%$ of cases [1, 2], whereas intermediate to late graft failure of vein grafts has occurred in $20 \%$ to $50 \%$ of cases within 5 years of surgery [3-5].

Thrombosis of infrainguinal bypass grafts usually results in a recrudescence of ischemic symptoms ranging from claudication to limb-threatening ischemia, especially in the case of diabetic foot ulcer. Previous reviews noted that $10 \%$ of patients underwent major amputation as the next intervention after failure of infrainguinal reconstruction [6].

The relatively high incidence of this complication and the major impact it has on patients mandate an aggressive and effective management regimen. For patients who have severe ischemia at the time of graft failure, the available therapeutic options have offered suboptimal results. Restoration of long-term patency to thrombosed vein or prosthetic infrainguinal bypass grafts with either thrombectomy or thrombolytic therapy has proved difficult [7-13]. Given the inability to restore patency effectively to failed 
infrainguinal bypass grafts after graft thrombosis, it appears that replacement of the failed graft with an entirely new bypass (i.e., a secondary bypass) is the best therapeutic option. Unfortunately, the results that have been achieved historically with secondary bypass have been markedly inferior to those after primary bypass grafting, with 5-year primary patency rates of $37 \%$ to $57 \%$ [8, 14-17].

Although balloon angioplasty for management of failing bypass grafts has been well documented, little mention has been made of its use in treating the occlusive lesion within the native artery after a failed bypass graft. Considerable advances in interventional technique, with the availability of steerable guidewires, low-profile balloon angioplasty catheters, and the development of subintimal angioplasty technique, allow an endovascular approach to arterial lesions previously confined to bypass surgery [18-21].

The purpose of our study was to describe the possible role of endovascular recanalization of the occluded native artery after a failed bypass graft in the case of either acute or chronic limb-threatening ischemia (CLI) otherwise leading to amputation.

\section{Materials and Methods}

\section{Study Design}

This study was a single-center, retrospective clinical analysis of 31 consecutive high-surgical-risk patients with CLI treated with percutaneous transluminal angioplasty (PTA)/stent following the failure of open surgery bypass graft reconstruction. Eligibility was based on the absence of healing ulcerations or gangrene for chronic cases and impending limb loss risk for acute cases.

All patients had occlusion of a previous bypass graft and were considered poor candidates for a new bypass operation on the basis of the absence of an adequate greater saphenous vein for distal bypass, presence of a poor distal bypass target vessel (no angiographically visible tibial vessels, vessels $\leq 1 \mathrm{~mm}$ in diameter, or diffusely diseased vessels), presence of severe comorbid conditions such as recent myocardial infarction ( $<6$ weeks), symptomatic coronary artery disease, or severe chronic obstructive pulmonary disease. Exclusion criteria included previous endarterectomy at the treatment site, pre-existing venous stasis ulcers, severe renal insufficiency (creatinine $>3.5 \mathrm{mg} / \mathrm{dL}$ ), untreated ipsilateral iliac stenosis $>70 \%$, and contraindication to intended medications.

Preprocedural and postprocedural ankle-brachial index $(\mathrm{ABI})$ and transcutaneous oxygen tension (tc- $\mathrm{O}_{2}$ ) were used to evaluate hemodynamic and tissue perfusion improvement. In all cases, patients were studied with colorDoppler ultrasound (color-Doppler US). MR angiography with MIP rotational protocol or MsCT angiography with three-dimensional reconstructions was used as a diagnostic preprocedure to define the location of lesions and to plan the revascularization strategy.

Ulcers on the lower limb were photographically recorded with a digital camera for core laboratory assessment. Photography was repeated at 3 and 6 months.

\section{Patient Population}

Based on these criteria, we collected 31 patients in whom revascularization was attempted in the period from January 2004 to March 2007 (21 men; mean age, 72.5 years; range, 46-87 years) for a total of 32 critically ischemic limbs. Risk factors are listed in Table 1. During the same period 28 limbs with critical ischemia following bypass failure underwent surgery.

Four $(12.5 \%)$ limbs presented with acute ischemia, and $28(87.5 \%)$ limbs with CLI. Three (9.3\%) limbs presented with suprainguinal bypass occlusions (1 aortobifemoral, 1 leg with aortobifemoral), $2(6.2 \%)$ with femoral-femoral crossover occlusions, $1(3.1 \%)$ with femoral-femoral crossover failure due to progression of atherosclerotic disease distal to the donor side and steal phenomenon, and $26(81.2 \%)$ with infrainguinal (femoral-popliteal) bypass occlusions. None of these patients had undergone previous PTA/stent interventions.

\section{Treatment}

Our procedural strategy was different in the case of acute or chronic ischemia from bypass graft occlusion. In patients with acute bypass occlusions we first attempted pharmacological fibrinolysis (i.e., urokinase infusion at $100 \mathrm{IU} / \mathrm{kg} / \mathrm{h}$ ) (Fig. 1) and/or thrombectomy with a Fogarty catheter and then proceeded to native artery recanalization only in the case of lysis failure. In patients with chronic

Table 1 Demographics

\begin{tabular}{ll}
\hline Variable & Data \\
\hline Mean age (yr) & 72.5 \\
Gender & \\
Male & 21 \\
Female & 10 \\
Diabetes & 21 \\
Coronary artery disease & 12 \\
Hypertension & 15 \\
Obesity & 13 \\
Smoker (even in the past) & 22 \\
Dyslipidemia & 12 \\
\hline
\end{tabular}


malfunction we directly performed a native artery recanalization.

All patients were started on ticlopidine, $250 \mathrm{mg}$ daily, and acetylsalicylic acid, $100 \mathrm{mg}$ daily ( 3 days before the procedure in the case of chronic bypass failure). The double antiaggregation was continued for 6 weeks after the procedure and acetylsalicylic acid was prescribed quoad vitam.

The endovascular procedure was performed in dedicated angiographic suites; an angiographic study was performed to quantify the extent of disease. Heparin sodium, $50 \mathrm{IU} / \mathrm{kg}$ i.v., was administered systematically. Angioplasty was performed for all patients through an ipsilateral antegrade common femoral approach for infrainguinal bypass failure or an omolateral plus contralateral retrograde femoral approach for suprainguinal bypass failure using various sizes of introducer sheaths, ranging from 5 to $7 \mathrm{Fr}$.

Iliac occlusions were always crossed intraluminally and stented. In occluded superficial femoral or popliteal arteries an angled 0.035 -in. hydrophilic guidewire (Terumo) was used to create an intentional subintimal way (Fig. 2). Occasionally, 3-mm balloon angioplasty of the first portion of the occlusion was required to facilitate crossing of the remaining tract. We stented the femoral artery only in the case of flow-limiting dissection or severe elastic recoil.

Dedicated 0.014-in. coronary guidewires (Choice Extra Support, PT-Graphix Super Support, Pilot 200) were used to cross infrapopliteal occlusive lesions intraluminally; in some cases an angled 0.035-in. stiff hydrophilic guidewire and a 4-Fr vertebral catheter (Terumo) were used to create an intentional subintimal way. Once occlusive lesions were crossed an angiography was performed to confirm distal
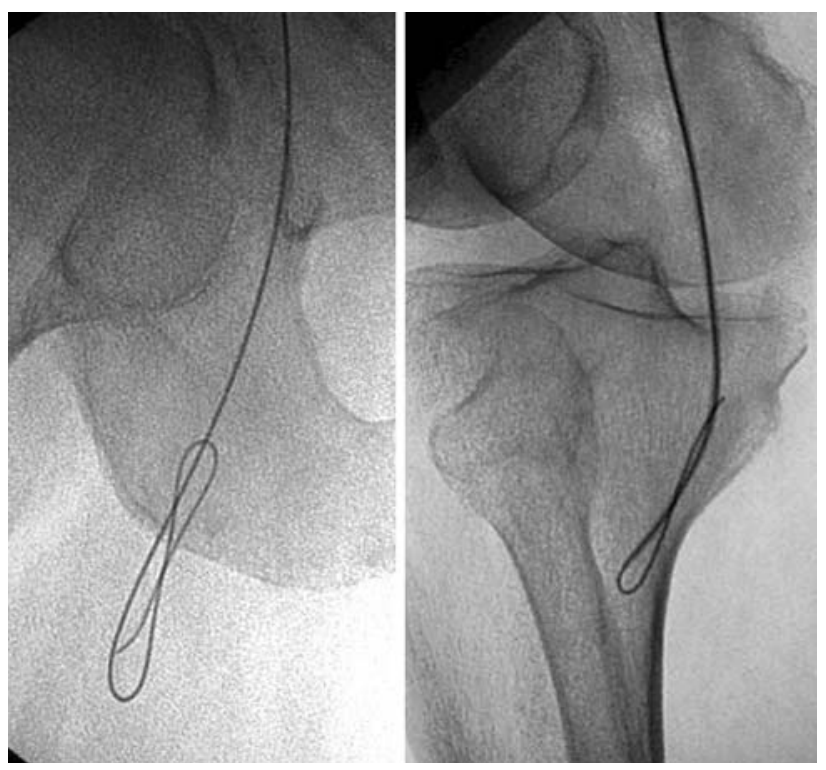

Fig. 2 After pharmacological lysis failure an intentional subintimal way was created through an ipsilateral antegrade common femoral approach

true lumen seating. Successful true lumen re-entry was defined as re-entry in the optimal angiographically defined target vessel beyond the occlusion without compromise of significant collaterals or branches.

PTA was performed using a 4- to 6-mm-diameter balloon in the superficial femoral and popliteal arteries and using 2- to 3-mm-diameter by 80 - to $150-\mathrm{mm}$-long lowprofile balloons (Invatec, Amphyrion Deep) in the tibial vessels. Balloon inflation times varied from 15 to $60 \mathrm{~s}$ at 8 to $14 \mathrm{~atm}$.
Fig. 1 Acute below-knee femoropopliteal bypass occlusion. The angiogram shows incomplete recanalization after pharmacological fibrinolysis
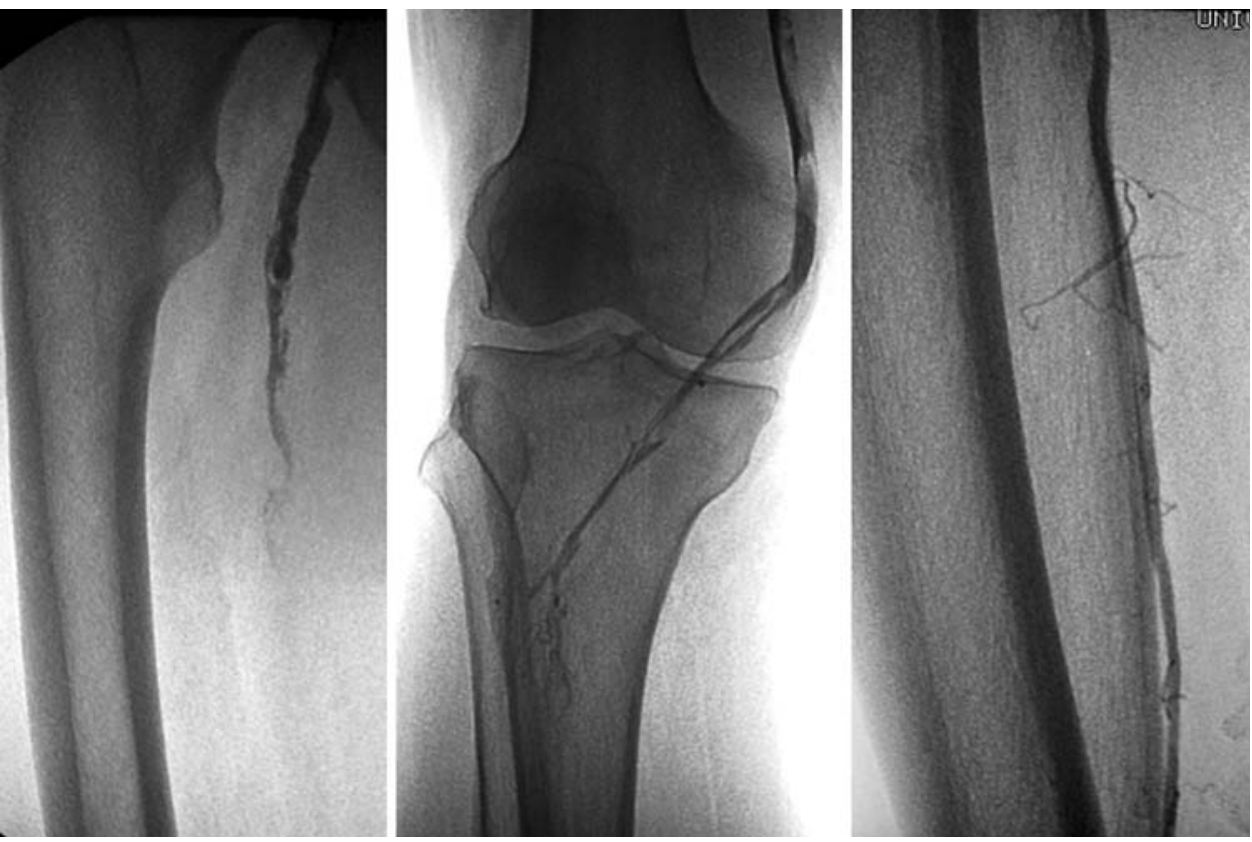
Technical success was defined as recovery of the native vessel with vascular lumen estimated as $>50 \%$ of the original lumen and absence of stasis of contrast medium in treated segments (Fig. 3).

Hemodynamic improvement was evaluated by increasing ABI [11]. Clinical success was defined as resolving rest pain, healing of an ulcer, avoidance of a major amputation, and an increase in percutaneous oxymetry $>50 \mathrm{mmHg}$.

Postprocedure follow-up, performed by Doppler US, percutaneous oxymetry, and clinical examination was scheduled at 1,3 , and 6 months and yearly thereafter.

\section{Results}

From January 2004 to March 2007 revascularization was attempted in 31 patients, for a total of 32 critically ischemic limbs. Distribution of the occluded segments in the study population was as indicated in Table 2 . The mean followup period was 24 months (range, 6-42 months). Two patients were lost to follow-up.

Technical success was achieved in 30 (93.7\%) of 32 limbs. Subintimal technique was used in $92.8 \%$ of infrainguinal arterial segments (always in the SFA). Mean lesion length was $20.3 \pm 6.3 \mathrm{~cm}$ (range, $12-45 \mathrm{~cm}$ ). In seven (21.8\%) limbs a stent was placed (always in the iliac artery). Two technical failures occurred in femoral-popliteal bypass occlusions, one caused by surgical disconnection of the
Table 2 Distribution of lesions in the study population

\begin{tabular}{ll}
\hline No. of limbs & Occluded segment(s) \\
\hline 6 & IA \\
8 & SFA \\
7 & SFA + PA \\
5 & SFA + PA + ATA + PTA \\
3 & SFA + ATA + PTA \\
3 & SFA + ATA + PTA + PerA \\
Total no. & \\
32 & 69 \\
\hline
\end{tabular}

native superficial femoral artery during bypass procedure. In this case a second graft was implanted, the other due to the absence of a patent pedal or plantar artery; this limb underwent amputation. In one case after successful recanalization and dilation, a distal thromboembolic occlusion occurred. This was resolved by catheter thrombus aspiration with a 6-Fr guiding catheter.

Clinical improvement with pain regression and ulcer healing followed each technical success. The ABI varied from $0.39 \pm 0.33$ to $0.85 \pm 0.20$ and the tc- $p \mathrm{O}_{2}$ always increased to $>50 \mathrm{mmHg}$.

During the follow-up period we observed an acute occlusion of a popliteal stent that underwent re-recanalization with release of an "intrastent" stent and four restenoses of the native artery (SFA) that were successfully redilatated. In five cases chronic obstruction of the entire
Fig. 3 The final angiogram shows complete recanalization of the native femoro popliteal artery. On the left frame previous graft proximal stump (curved arrow) is visible
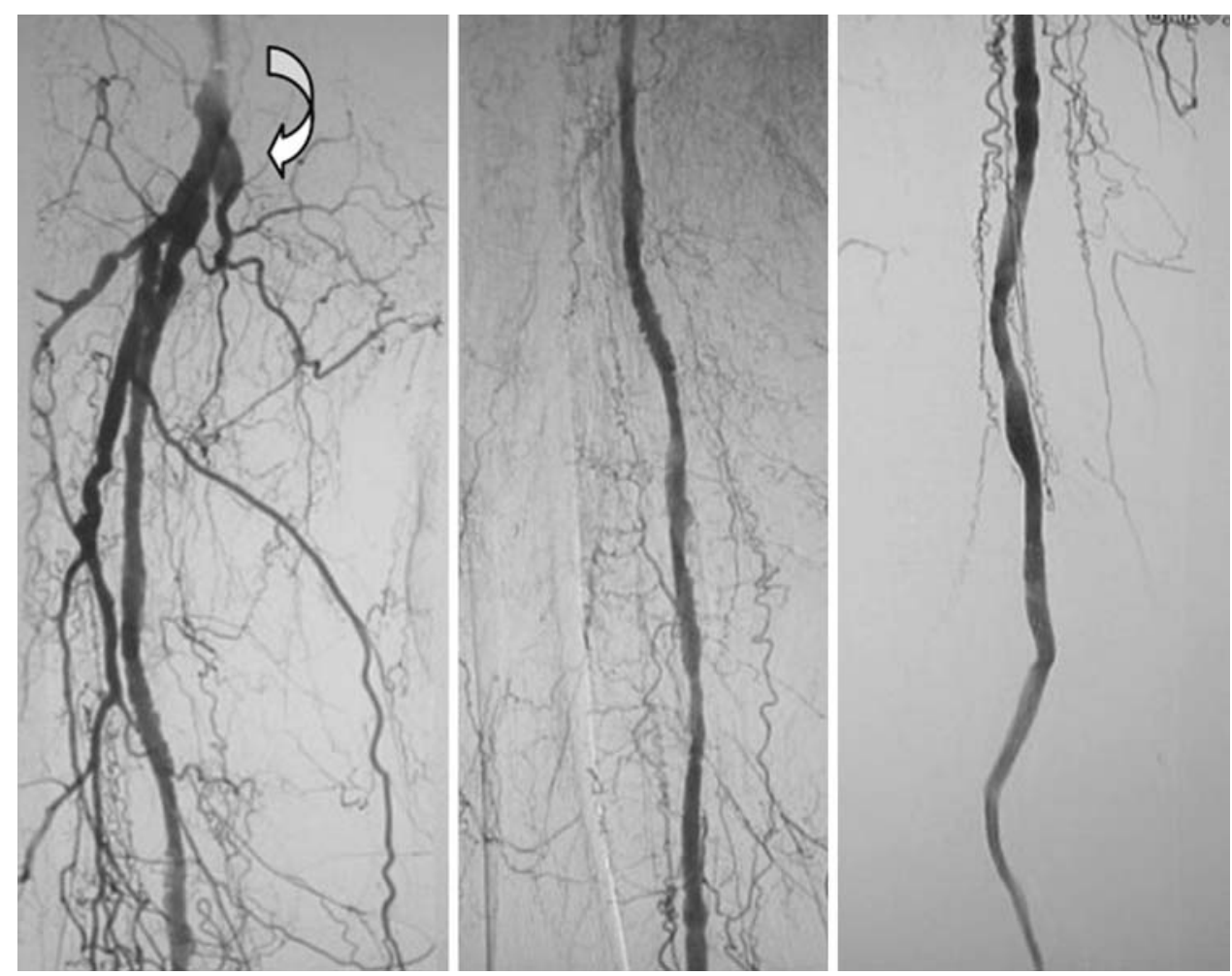
femoropopliteal tract redeveloped, with worsening of the limb clinical status, requiring amputation in two cases; the other three cases were successfully managed with successful re-recanalization (one limb) and medical therapy (two limbs). Two patients died from myocardial infarction. The cumulative primary assisted patency calculated by Kaplan-Meyer analysis was $92 \%$ and $88 \%$, respectively, at 12 and 24 months (Table 3). The cumulative secondary patency calculated by Kaplan-Meyer analysis was $96 \%$ and $84 \%$, respectively, at 12 and 30 months (Table 4).

Limb salvage results were considerably better as calculated by Kaplan-Meyer analysis, with a rate approaching $90 \%$ at 30 months (Table 5).

\section{Discussion}

Bypass graft failure presents a major challenge to the vascular surgeon. Correct management in any particular patient varies with a number of fundamental considerations. Most important are the functional status of the patient and the condition of the affected extremity. A significant proportion of patients will appear well compensated after graft thrombosis, with relatively mild disability not warranting intervention. Similarly, patients whose general health status has declined to the point where active ambulation is no longer realistic may benefit most from simple observation. The majority of patients who were originally operated on for severe ischemia, however, will

Table 3 Cumulative primary assisted patency calculated by KaplanMeyer analysis

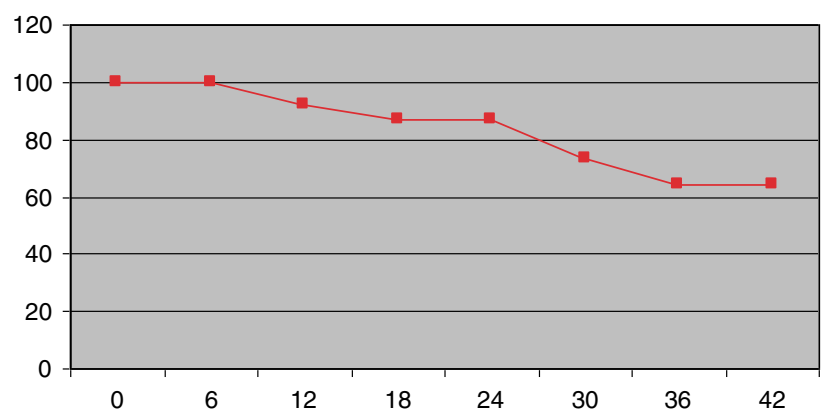

\begin{tabular}{cccccccc}
\hline $\begin{array}{c}\text { Months of } \\
\text { follow-up }\end{array}$ & $\begin{array}{c}\text { Death or } \\
\text { Lost to } \\
\text { follow-up }\end{array}$ & $\begin{array}{c}\text { Legs } \\
\text { observe } \\
\text { d before } \\
\mathrm{t}\end{array}$ & $\begin{array}{c}\text { Events per } \\
\text { period }\end{array}$ & Survival rate & $\begin{array}{c}\text { Patency } \\
\text { rate }\end{array}$ & $\begin{array}{c}\text { Standard } \\
\text { error }\end{array}$ & $\begin{array}{c}\text { Standard error } \\
\text { percent }\end{array}$ \\
\hline $\mathrm{t}$ & & $\mathrm{n}$ & $\mathrm{f}$ & $\mathrm{p}$ & $\mathrm{S}(\mathrm{t})$ & $\mathrm{SE}$ & $\mathrm{SE} \%$ \\
\hline 6 & 0 & 30 & 0 & 1.000 & 1.000 & 0.000 & 0.000 \\
12 & 1 & 25 & 2 & 0.920 & 0.920 & 0.052 & 5.204 \\
18 & 0 & 22 & 1 & 0.955 & 0.878 & 0.065 & 6.535 \\
24 & 2 & 18 & 0 & 1.000 & 0.878 & 0.072 & 7.224 \\
30 & 0 & 12 & 2 & 0.833 & 0.732 & 0.109 & 10.940 \\
36 & 1 & 8 & 1 & 0.875 & 0.640 & 0.136 & 13.577 \\
42 & 0 & 3 & 0 & 1.000 & 0.640 & 0.222 & 22.172 \\
\hline
\end{tabular}

Table 4 Cumulative secondary patency calculated by Kaplan-Meyer analysis

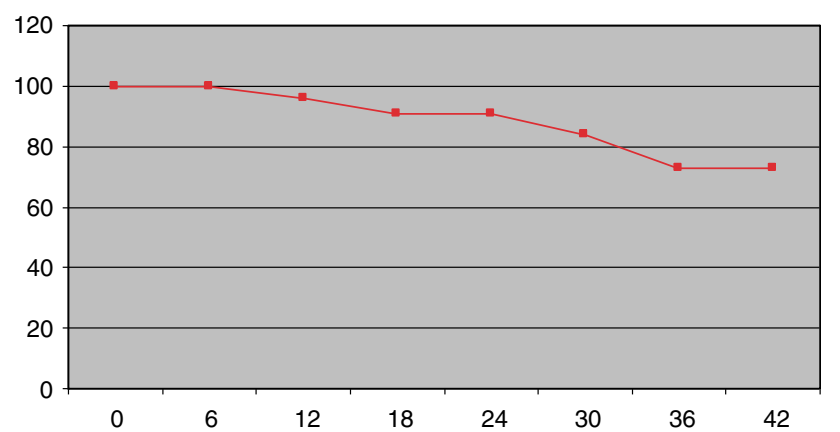

\begin{tabular}{cccccccc}
\hline $\begin{array}{c}\text { Months of } \\
\text { follow-up }\end{array}$ & $\begin{array}{c}\text { Death or } \\
\text { Lost to } \\
\text { follow-up }\end{array}$ & $\begin{array}{c}\text { Legs } \\
\text { obsenved } \\
\text { betore t }\end{array}$ & $\begin{array}{c}\text { Events per } \\
\text { period }\end{array}$ & Survival rate & $\begin{array}{c}\text { Patency } \\
\text { rate }\end{array}$ & $\begin{array}{c}\text { Standard } \\
\text { error }\end{array}$ & $\begin{array}{c}\text { Standarc error } \\
\text { percent }\end{array}$ \\
\hline $\mathrm{t}$ & & $\mathrm{n}$ & $\mathrm{f}$ & $\mathrm{p}$ & $\mathrm{S}(\mathrm{t})$ & $\mathrm{SE}$ & $\mathrm{SE} \%$ \\
\hline 6 & 0 & 30 & 0 & 1.000 & 1.000 & 0.000 & 0.000 \\
12 & 1 & 25 & 1 & 0.960 & 0.960 & 0.038 & 3.840 \\
18 & 0 & 22 & 1 & 0.955 & 0.916 & 0.057 & 5.650 \\
24 & 2 & 18 & 0 & 1.000 & 0.916 & 0.062 & 6.246 \\
30 & 0 & 12 & 1 & 0.917 & 0.840 & 0.097 & 9.699 \\
36 & 1 & 8 & 1 & 0.875 & 0.735 & 0.134 & 13.377 \\
42 & 0 & 3 & 0 & 1.000 & 0.735 & 0.218 & 21.845 \\
\hline
\end{tabular}

suffer recurrent limb-threatening ischemia or severe disability from symptoms of claudication at the time of graft failure. These patients require revascularization for limb

Table 5 The cumulative limb survive calculated by Kaplan-Meyer analysis

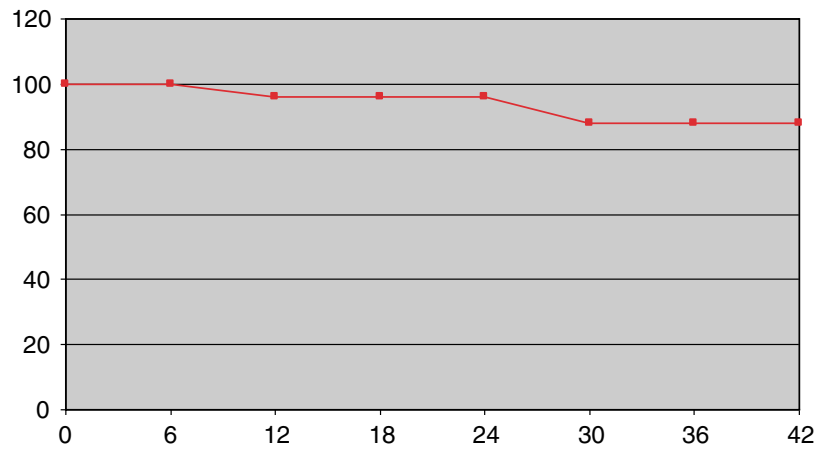

\begin{tabular}{cccccccc}
\hline $\begin{array}{c}\text { Months of } \\
\text { follow-up }\end{array}$ & $\begin{array}{c}\text { Death or } \\
\text { Lost to } \\
\text { follow-up }\end{array}$ & $\begin{array}{c}\text { Legs } \\
\text { observed } \\
\text { before t }\end{array}$ & $\begin{array}{c}\text { Events per } \\
\text { period }\end{array}$ & Survival rate & $\begin{array}{c}\text { Patency } \\
\text { rate }\end{array}$ & $\begin{array}{c}\text { Standard } \\
\text { error }\end{array}$ & $\begin{array}{c}\text { Standard error } \\
\text { percent }\end{array}$ \\
\hline $\mathrm{t}$ & & $\mathrm{n}$ & $\mathrm{f}$ & $\mathrm{p}$ & $\mathrm{S}(\mathrm{t})$ & $\mathrm{SE}$ & $\mathrm{SE} \%$ \\
\hline 6 & 0 & 30 & 0 & 1.000 & 1.000 & 0.000 & 0.000 \\
12 & 1 & 25 & 1 & 0.960 & 0.960 & 0.038 & 3.840 \\
18 & 0 & 22 & 0 & 1.000 & 0.960 & 0.041 & 4.093 \\
24 & 2 & 18 & 0 & 1.000 & 0.960 & 0.045 & 4.525 \\
30 & 0 & 12 & 1 & 0.917 & 0.880 & 0.088 & 8.800 \\
36 & 1 & 8 & 0 & 1.000 & 0.880 & 0.108 & 10.778 \\
42 & 0 & 3 & 0 & 1.000 & 0.880 & 0.176 & 17.600 \\
\hline
\end{tabular}


Table 5 continued

\begin{tabular}{|c|c|c|c|c|c|c|c|c|c|}
\hline $\mathbf{n}^{\circ}$ & age & sex & $\begin{array}{c}\text { risk } \\
\text { factors }\end{array}$ & $\begin{array}{c}\text { bypass } \\
\text { type }\end{array}$ & $\begin{array}{c}\text { native artery } \\
\text { recanalized }\end{array}$ & initial success & & Follow up & \\
\hline 1 & 46 & $\mathrm{~m}$ & $\mathrm{~d}, \mathrm{c}, \mathrm{h}, \mathrm{s}, \mathrm{dy}$ & bkfp & $\begin{array}{c}\mathrm{SFA}+\mathrm{ATA}+ \\
\text { PTA }\end{array}$ & & & $\begin{array}{c}\text { SFA stenosis } \\
@ 16 \mathrm{~m}\end{array}$ & PTA \\
\hline 2 & 78 & $m$ & $\mathrm{~d}, \mathrm{~h}, \mathrm{o}$ & $a b f$ & IA & & & & \\
\hline 3 & 74 & $f$ & d,c,h,s & bkfp & $\begin{array}{c}\text { SFA + ATA + } \\
\text { PTA + PerA }\end{array}$ & & & & \\
\hline 4 & 68 & $\mathrm{~m}$ & $\mathrm{~s}, \mathrm{dy}$ & bkfp & $\mathrm{SFA}+\mathrm{PA}$ & & & & \\
\hline 5 & 75 & $\mathrm{~m}$ & $\mathrm{~d}, \mathrm{c}, \mathrm{h}$ & akfp & SFA & & & & \\
\hline 6 & 78 & $f$ & d,o,s,dy & bkfp & $\mathrm{SFA}+\mathrm{PA}$ & $\begin{array}{c}\text { technical failure } \\
\text { (probable sfa } \\
\text { ligation) }\end{array}$ & $\begin{array}{l}\text { redo } \\
\text { bypass }\end{array}$ & & \\
\hline 7 & 74 & $\mathrm{~m}$ & $d, h, o, s$ & akfp & SFA & & & $\begin{array}{l}\text { cronic femoral } \\
\text { occlusion @ } \\
30 \mathrm{~m}\end{array}$ & $\begin{array}{c}\text { succesfully } \\
\text { recanalized } \\
\text { and } \\
\text { stented }\end{array}$ \\
\hline 8 & 73 & $\mathrm{~m}$ & d,c,h,s & bkfp & $\begin{array}{l}\text { SFA + PA + } \\
\text { ATA + PTA }\end{array}$ & & & & \\
\hline 9 & 77 & $\mathrm{~m}$ & s, dy & bkfp & $\begin{array}{c}\text { SFA + ATA + } \\
\text { PTA }\end{array}$ & & & & \\
\hline 10 & 68 & $f$ & d,h,o & $\mathrm{ff}$ & IA & & & & \\
\hline 11 & 74 & $m$ & $\mathrm{~d}, \mathrm{o}$ & $a b f$ & $\mathrm{IA}+\mathrm{IA}$ & & & & \\
\hline 12 & 78 & $\mathrm{~m}$ & $\mathrm{~d}, \mathrm{c}, \mathrm{h}$ & akfp & SFA & & & $\begin{array}{c}\text { SFA stenosis } \\
@ 22 \mathrm{~m}\end{array}$ & PTA \\
\hline 13 & 76 & $\mathrm{~m}$ & s, dy & bkfp & $\begin{array}{c}\text { SFA + ATA + } \\
\text { PTA + PerA }\end{array}$ & & & & \\
\hline 14 & 77 & $\mathrm{~m}$ & d,h,o & bkfp & $\begin{array}{l}\text { SFA + PA + } \\
\text { ATA + PTA }\end{array}$ & $\begin{array}{c}\text { technical failure } \\
\text { (absence of } \\
\text { pedal/plantar } \\
\text { artery) } \\
\end{array}$ & $\begin{array}{c}\text { amputatio } \\
n\end{array}$ & & \\
\hline 15 & 70 & $f$ & $\mathrm{~d}, \mathrm{c}, \mathrm{h}, \mathrm{o}, \mathrm{s}$ & bkfp & SFA + PA & & & & \\
\hline 16 & 72 & $\mathrm{~m}$ & s,dy & bkfp & $\mathrm{SFA}+\mathrm{PA}$ & & & & \\
\hline 17 & 76 & $\mathrm{~m}$ & $\mathrm{~d}, \mathrm{o}, \mathrm{s}$ & akfp & SFA & & & & \\
\hline 18 & 76 & $\mathrm{~m}$ & s,dy & $\mathrm{ff}$ & IA & & & & \\
\hline 19 & 74 & $f$ & $\mathrm{~d}, \mathrm{c}, \mathrm{h}, \mathrm{o}, \mathrm{s}$ & bkfp & $\mathrm{SFA}+\mathrm{PA}$ & & & $\begin{array}{c}\text { acute popliteal } \\
\text { occlusion @ } \\
12 \mathrm{~m} \\
\end{array}$ & $\begin{array}{l}\text { succesfully } \\
\text { recanalized }\end{array}$ \\
\hline 20 & 78 & $m$ & s,dy & akfp & SFA & & & & \\
\hline 21 & 69 & $f$ & $\mathrm{~h}, \mathrm{~s}$ & akfp & SFA & & & & \\
\hline 22 & 68 & $\mathrm{~m}$ & d,c,h,o & bkfp & $\begin{array}{l}\text { SFA + PA + } \\
\text { ATA + PTA }\end{array}$ & & & $\begin{array}{c}\text { cronic } \\
\text { infrapopliteal } \\
\text { occlusion @ } \\
18 \mathrm{~m}\end{array}$ & $\begin{array}{l}\text { medical } \\
\text { terapy }\end{array}$ \\
\hline 23 & 75 & $\mathrm{~m}$ & d,h,o,s & akfp & $\begin{array}{c}\text { SFA + ATA + } \\
\text { PTA }\end{array}$ & $\begin{array}{c}\text { distal } \\
\text { thromboembolic } \\
\text { occlusion }\end{array}$ & $\begin{array}{c}\text { catheter } \\
\text { thrombus } \\
\text { aspiration }\end{array}$ & & \\
\hline 24 & 71 & $\mathrm{~m}$ & s, dy & bkfp & $\begin{array}{c}\text { SFA + ATA + } \\
\text { PTA + PerA }\end{array}$ & & & $\begin{array}{c}\text { cronic } \\
\text { infrapopliteal } \\
\text { occlusion @ } \\
18 \mathrm{~m} \\
\end{array}$ & $\begin{array}{c}\text { medical } \\
\text { terapy }\end{array}$ \\
\hline 25 & 67 & $\mathrm{~m}$ & d,c,h,o & $\mathrm{ff}$ & IA & & & & \\
\hline 26 & 74 & $\mathrm{~m}$ & s, dy & akfp & SFA & & & $\begin{array}{c}\text { SFA stenosis } \\
@ 32 \mathrm{~m}\end{array}$ & PTA \\
\hline 27 & 65 & $f$ & $\mathrm{~d}, \mathrm{c}, \mathrm{s}$ & bkfp & $\begin{array}{l}\text { SFA + PA + } \\
\text { ATA + PTA }\end{array}$ & & & & \\
\hline 28 & 78 & $\mathrm{~m}$ & $\mathrm{~d}, \mathrm{c}, \mathrm{o}, \mathrm{s}$ & bkfp & $\mathrm{SFA}+\mathrm{PA}$ & & & $\begin{array}{l}\text { SFA stenosis } \\
\text { @ } 6 \mathrm{~m}+\text { cronic } \\
\text { femoropopliteal } \\
\text { occlusion @ } \\
30 \mathrm{~m}\end{array}$ & $\begin{array}{c}\text { successfull } \\
\text { PTA @ } 6 \mathrm{~m} \\
+ \\
\text { amputation } \\
\text { @ } 30 \mathrm{~m}\end{array}$ \\
\hline 29 & 76 & $f$ & $\mathrm{~d}, \mathrm{~s}, \mathrm{dy}$ & bkfp & $\begin{array}{l}\text { SFA + PA + } \\
\text { ATA + PTA }\end{array}$ & & & $\begin{array}{c}\text { cronic } \\
\text { infrapopliteal } \\
\text { occlusion @ } \\
12 \text { m }\end{array}$ & amputation \\
\hline 30 & 69 & $f$ & s,dy & akfp & SFA & & & & \\
\hline 31 & 74 & $f$ & d,c & bkfp & $\mathrm{SFA}+\mathrm{PA}$ & & & & \\
\hline
\end{tabular}

preservation and maintenance of independent function. Unfortunately, restoration of durable patency to failed infrainguinal grafts has generally not been attainable. Thrombectomy and revision of thrombosed grafts have resulted in patency rates of only $19 \%$ to $28 \%$ at the 5-year interval for failed vein grafts $[7,8]$. Long-term results after thrombectomy of polytetrafluoroethylene grafts have been even poorer, with patency rates of $32 \%$ at 2.5 years and $11 \%$ at 5 years $[9,10]$. Thrombolysis of occluded infrainguinal bypass grafts followed by graft revision has also resulted in the low patency rates of $0 \%$ to $37 \% 1$ to 3 years after treatment for both prosthetic and vein 
conduits [11-13]. In several reports, thrombectomy or thrombolysis of failed infrainguinal grafts represents a temporary measure, with the majority of patients requiring an ongoing series of reinterventions to maintain graft patency. Thus it is believed that the majority of patients with failed bypass grafts and recurrent ischemia should be treated with an entirely new secondary bypass graft. Thrombectomy and thrombolysis of occluded grafts are generally reserved for selected cases based on the timing of graft occlusion, the condition of the original conduit, and the complete absence of autogenous, including ectopic, veins [22].

Given the general commitment to a new bypass graft as the preferred mode of revascularization after infrainguinal graft failure, and the historically inferior results of secondary bypass compared with primary bypass, we undertook this review to determine the preferred strategies for and current results of the endovascular approach to native artery occlusion after a failed bypass graft in the case of either acute or CLI otherwise leading to amputation.

In our study limb-salvage angioplasty has been introduced as an alternative last-chance method, with the primary goal of achieving limb salvage in selected poor surgical candidates with end-stage arterial occlusive disease following bypass failure. We hypothesized that PTA of the native artery in these patients may lead to a significantly improved limb-salvage rate, with low morbidity and mortality compared with primary amputation. Only anecdotal experiences have been previously reported in the literature, such as that by Hasim et al., who described two cases of recanalization of native arteries, with patency achieved at 18 and 11 months, respectively [23].

Our technical and clinical success rate was $93.3 \%$. A more detailed investigation of one technical failure (femoral-popliteal bypass occlusion patient) based on an analysis of the surgical report recalled from other hospital archives showed that failure of recanalization was due to surgical disconnection of the SFA and terminoterminal proximal anastomosis of the bypass graft. This is not a conventional technique used in vascular surgery practice but this evidence was nonetheless found. The other technical failure was attributable to the lack of a patent artery in the foot after occlusion of a femorotibial bypass graft. Our opinion is that successful recanalization of the arterial tract previously considered unsuitable for an endovascular approach is now enabled by the improved competency and experience of vascular specialists, especially in subintimal angioplasty technique [18-21], as well as the advances made in catheter and guidewire technology.

More encouraging are the results in terms of limb salvage (90\% at 42 months) compared to redo surgery after bypass failure; this is probably due to collateral pathway preservation during native artery recanalization. Even in the case of arterial reocclusion, after wound healing mild blood flow is generally required to maintain tissue integrity Therefore, temporary (1- to 6-month) restoration of "straight-line" flow to the foot may be sufficient to relieve CLI.

\section{Conclusion}

Our experience shows the feasibility of occluded native artery endovascular recanalization in the case of severe acute or CLI after a failed bypass graft, with optimal results in terms of midterm arterial patency and limb salvage.

The increasingly aggressive percutaneous therapy of arterial occlusive disease allowed by considerable advances in interventional skills, especially the development of subintimal angioplasty technique, may now be expanded to include a group of patients with acute or chronically failed bypass grafts and occlusive disease within the native artery. This group of patients would previously have been relegated to repeat bypass grafts, with their inherently inferior patency and recognized added technical demands. We recognize previous surgical native artery disconnection and lack of pedal runoff to be the main cause of technical failure.

\section{References}

1. Brewster DC, LaSalle AJ, Robison JG et al (1984) Femoropopliteal graft failures: clinical consequences and success of secondary reconstructions. Arch Surg 118:1043-1050

2. Rutherford RB, Jones DN, Bergentz S et al (1984) The efficacy of dextran 40 in preventing early postoperative thrombosis following difficult lower extremity bypass. J Vasc Surg 1:765-771

3. Donaldson MC, Mannick JA, Whittemore AD (1991) Femoraldistal bypass with in situ greater saphenous vein: long term results using the Mills valvulatome. Ann Surg 213:457-465

4. Leather KP, Shah DJ, Chang BB et al (1988) Resurrection of the in situ saphenous vein bypass: 1000 cases later. Ann Surg 208: 435-442

5. Taylor LM, Edwards JM, Porter JM (1990) Present status of reversed vein bypass grafting: five year results of a modern series. J Vasc Surg 11:193-206

6. Donaldson MC, Mannick JA, Whittemore AD (1992) Causes of primary graft failure after in situ saphenous vein bypass grafting. J Vasc Surg 15:113-120

7. Cohen JR, Mannick JA, Couch NP et al (1986) Recognition and management of impending vein graft failure. Arch Surg 121: 758-759

8. Whittemore AD, Clowes AW, Couch NP et al (1981) Secondary femoropopliteal reconstruction. Ann Surg 193:35-42

9. Qnifiones-Baldrich WJ, Prego A, Ucelay-Gomez R et al (1991) Failure of PTFE infrainguinal revascularization: patterns, management alternatives and outcome. Ann Vasc Surg 5:163-169

10. Whittemore AD, Kent CK, Donaldson MC et al (1989) What is the role of polytetrafluoroethylene grafts in infrainguinal reconstruction? J Vasc Surg 10:299-305

11. Belkin M, Donaldson MC, Whittemore AD et al (1990) Observations on the use of thrombolytic agents for thrombotic occlusions of infrainguinal vein grafts. J Vasc Surg 11:289-296 
12. Graor RA, Risus B, Young JR et al (1988) Thrombolysis of peripheral arterial bypass grafts: surgical thrombectomy compared with thrombolysis. J Vasc Surg 7:347-355

13. Parent FN, Prowski JJ, Bernhard VM et al (1991) Outcome of intraarterial urokinase for acute vascular occlusion. J Cardiovasc Surg 32:680-690

14. Edwards JE, Taylor LM, Porter JM (1990) Treatment of failed lower extremity bypass grafts with new autogenous vein bypass grafting. J Vasc Surg 11:136-145

15. Bartlett ST, Olinde AJ, Flinn WR et al (1987) The reoperative potential of infrainguinal bypass: long-term limb and patient survival. J Vasc Surg 5:170-179

16. Ascer E, Collier P, Gupta SK, Veith FJ (1987) Reoperation for polytetrafluoroethylene bypass failure: the importance of distal outflow site and operative technique in determining outcome. $\mathrm{J}$ Vasc Surg 5:298-310

17. Yang PM, Wengerter KR, Veith FJ et al (1991) Value and limitations of secondary femoropopliteal bypasses with polytettattuoroethylene. J Vasc Surg 14:292-298
18. Met R, Van Lienden KP, Koelemay MJ, Bipat S, Legemate DA, Reekers JA (2008) Subintimal angioplasty for peripheral arterial occlusive disease: a systematic review. Cardiovasc Interv Radiol 31(4):687-697

19. Loftus IM, Hayes PD, Bell PR (2004) Subintimal angioplasty in lower limb ischaemia. Cardiovasc Surg (Torino) 45(3):217-229

20. Scott EC, Biuckians A, Light RE, Scibelli CD, Milner TP, Meier GH III, Panneton JM (2007) Subintimal angioplasty for the treatment of claudication and critical limb ischemia: 3-year results. J Vasc Surg 46(5):959-964

21. Gandini R, Pipitone V, Stefanini M, Maresca L, Spinelli A, Colangelo V, Reale CA, Pampana E, Simonetti G (2007) The "Safari" technique to perform difficult subintimal infragenicular vessels. Cardiovasc Interv Radiol 30(3):469-473

22. Belkin M (1993) Thrombolytic therapy for arterial occlusive disease. Adv Vasc Surg 1:189-211

23. Harward TRS, Coe D, Flynn TC, Seeger JM (1992) The use of arm vein conduits during infrageniculate arterial bypass. J Vasc Surg 16:420-427 